\title{
Psychological Distress in Anorectic Women, Their Fathers and Mothers
}

\author{
Elisabeth Bratt Neuberg \\ Linköping University, \\ Linköping, Sweden
}

\author{
Gerhard Andersson \\ Linköping University, Linköping; Karolinska Institutet, \\ Stockholm, Sweden
}

\begin{abstract}
Background: The aim of this study was to investigate self-reported psychological distress in anorectic women, their father and mother. In addition, two other groups of young women and their parents were included. In total, there were three groups consisting of women between 18-30 years with anorexia nervosa (AG), drug-dependency problems (DG), students (SG) without significant problems and the parents of all three groups. The diagnoses of anorexia were made according to DSM-IV. Methods: Several methods were used. The Karolinska Scale of Personality (KSP) (Schalling, Åsberg, Edman, \& Oreland, 1987) was the focus of this study. Results: Anorectic women (AG) reported higher levels of psychological distress compared to the students (SG) but less than the drug-dependent women (DG). The fathers of the anorexia nervosa women (AG) did not differ on the different scales from the other fathers. This indicates that anorectic women do not have fathers with elevated psychological distress. A significant effect on the scale of somatic anxiety (KPSA) was the only difference found between the mothers, where AG was in the middle between SG with the highest scores and DG with the lowest scores. Differences in psychological distress within families were also tested showing that anorectic women differed from their mothers and fathers. We found an indication that mothers of anorectic women reported more anxiety than the fathers. Conclusion: In conclusion, this study illustrates the importance of studying mothers and fathers of women with anorexia.
\end{abstract}

Keywords: anorectic women, fathers, mothers, between families, within families

\section{Introduction}

Anorexia is a complex condition (Strober \& Johnson, 2012). The role of the father in the life of the anorectic women is a comparatively unexplored area (Phares, 1992; Bornstein, 1993; Phares, 2005). Research on Anorexia Nervosa (AN) has mainly focused on the relation between the anorectic daughter and her mother, on family pattern and the biological correlates. There are however a few papers on the father's role. Jeammet, Gorge, Zweifel, and Flavigny (1973) identified the anorectic girl's father and identified four categories: the "absent" father, the "blurred" father, the father with "contra oedipal orientation", that is an erotized relation and the father with "maternal orientation". Engel and Stienen (1988) on the other hand identified four categories: the "bonding", the "brutal", the "weak" and the "absent" father. The two first categories of fathers were

Elisabeth Bratt Neuberg, Licensed Psychologist, Licensed Psychotherapist, Department of Behavioral Sciences and Learning, Linköping University.

Gerhard Andersson, Department of Behavioral Sciences and Learning, Linköping University; Department of Clinical Neuroscience, Psychiatry section, Karolinska Institutet. 
overrepresented as fathers of anorectic daughters. Gale, Cluett, and Laver-Bradbury (2013) argued that there are disproportionately fewer studies examining the role of the father in the development of child and adolescent psychopathology, and in particular in the field of eating disorders. Botta and Dumlao (2002) focused on the underlying patterns of father-child communication. They found that the communication patterns were moderately linked to anorexia. The question of parental protection and psychological control has been the focus of several studies paternal, among them has the overprotection been pointed out by Eme and Danielek (1995).

Thus, there is a need to further the understanding of the role of the father for his anorectic daughter. The aim of this study was to investigate self-reported psychological distress in anorectic women and their fathers and mothers.

\section{Method}

\section{Participants and Procedure}

The three groups investigated were: (1) The Anorectic Group (AG); (2) The Drug-Dependent Group (DG); and (3) The Student Group (SG). The anorectic and the drug-dependent women were diagnosed according to DSM-IV-TR (APA 2000) and ICD-10 (WHO 2007). All the young women and their families were recruited in Stockholm. The AG from Stockholm Center for Anorexia Center (SCFA), previously called EMBLA, the DG from the Center Therapy and Evaluation of Drugs and Medications (TUB), and the SG from Adult High School, called ÅSÖ. In total 137 persons participated, with 52 daughters, 43 fathers and 42 mothers. The participants were given the questionnaire in connection with the first or second interview and they had the choice to answer it directly or return it at the following meeting. Most of the participants would fill it in directly following informed consent (see Table 1 for further description).

Table 1

Number and Mean Age of Years of Participants

\begin{tabular}{lllllll}
\hline & \multicolumn{2}{l}{ Anorexia Group } & \multicolumn{2}{l}{ Drug-dependency Group } & \multicolumn{2}{l}{ Student Group } \\
\hline & $N$ & Age & $N$ & Age & $N$ & Age \\
Daughters & 17 & $(M)(S D)$ & & $(M)(S D)$ & & $22(S D)$ \\
Fathers & 17 & $24(3.2)$ & 17 & $26(2.5)$ & 18 & $52(9.3)$ \\
Mothers & 18 & $55(6.0)$ & 13 & $55(6.3)$ & 13 & $51(7.01)$ \\
\hline
\end{tabular}

Notes. $N$ : Number; $M$ : Mean; $S D$ : Standard deviation.

\section{Instrument}

The Karolinska scales of Personality (KSP) (af Klinteberg, Schalling, \& Magnusson, 1986; Schalling \& Edman, 1987; Schalling et al., 1987), a personality inventory, was used to measure self-reported psychological distress, as it explores and has the aim to understand complicated relations between individual differences in behavior, affectivity and functioning and their physical correlates. KSP is built on 135 statements measuring 18 subscales (see Table 2). They are organized around four temperamental dimensions; Aggression/Hostility (i.e., guilt, indirect aggression, irritability, suspicion, and verbal aggression); Anxiety (i.e., inhibition of aggression, muscular tension, psychasthenia, psychic anxiety, and somatic anxiety); Conformity versus non-conformity (i.e., socialization and social desirability); Introversion-Extraversion (i.e., detachment, impulsiveness, and monotony-avoidance) (Dåderman, Hellström, Wennberg, \& Törestad, 2005). The response format in the KSP is a four-step scale, from "Does not apply at all" (scored 1) to "Applies completely" (scored 4). Nine of the 
KSP scales consist of 10 items, one scale (Socialization) includes 20 items and all hostility and aggressiveness-related scales consist of five items each (Gustavsson, 1997). The scales have shown good validity and reliability (Ahrén-Monga, Holmgren, Knorring, \& Klinteberg, 2008).

Table 2

Descriptions of Highs Scores for Different Scales in Karolinska Scales of Personality (KSP) (Nielsen, 2015)

\begin{tabular}{lll}
\hline & Personality scales & Descriptions \\
\hline 1. & Somatic Anxiety (SA) & Autonomic disturbances, restless, panicky \\
2. & Psychic Anxiety (PA) & Worrying, lack of self-confidence, sensitive \\
3. & Muscular Tension (MT) & Tense, unable to relax \\
4. & Multicomponent Anxiety (MCA) & $\{1+2+3\}$ \\
5. & Social Desirability (SD) & Social conformity, polite \\
6. & Impulsiveness (I) & Impulsive actions, acting on the spur of the moment \\
7. & Monotony Avoidance (MA) & Need for change and action, avoiding routine \\
8. & Detachment (De) & Avoiding close interactions with others, distanced \\
9. & Psychastenia (Ps) & Easily fatigued \\
10. & Socialization (So) & Positive childhood experiences, good adjustment \\
11. & Indirect Aggression (IA) & Showing anger indirectly, sulking, \\
12. & Verbal Aggression (VA) & Expressing anger verbally, getting into arguments \\
13. & Irritability (IRR) & Irritable, lack of patience \\
14. & Suspicion (S) & Suspicious, distrusting \\
15. & Guilt (G) & Remorseful, ashamed of bad thoughts. \\
16. & Aggression (AGG) & $\{11+12+13\} /$ IA + VA + IRR \\
17. & Hostility (HOST) & $\{14+15\} / A G G+$ HOST \\
18. & Inhibition of Aggression (Inh) & Inability to speak up, non-assertive \\
\hline & &
\end{tabular}

\section{Results}

\section{Comparison Between the Daughters}

Analyses of variance with Bonferroni post hoc tests showed significant group effects for the daughters in the three groups on the scales of muscular tension (KSPMT), multicomponent anxiety (KSPMCA), impulsivity (KSPI), monotony avoidance (KSPMA), psychastenia (KSPPS) and socialization (KSPSO).

Bonferroni post hoc tests showed significant differences between the anorectic women (AG) and the drug dependent women (DG) on the scales of impulsivity (KSPI) $(p<0.05)$. Significant differences were found between the women with drug-dependency (DG) and the student (SG) on the scales of muscular tension (KSPMT) $(p<0.01)$, multicomponent anxiety (KSPMCA), monotony avoidance (KSPMA), psychastenia (KSPPS) at the level $p<0.05$, socialization (KSPSO) at the level of $p<0.001$.

Data are displayed in Figure 1 (in all figures only significant differences as displayed).

\section{Comparisons Between the Fathers}

There were no significant differences between the Fathers in the three groups. Data not shown.

\section{Comparison Between the Mothers}

There was a significant effect on the scale of somatic anxiety (KPSA). The scores for the mothers (AG) lie in the middle $(M=18.17, S D=5.17)$ in comparison with the mothers $(\mathrm{DG})$ with the lowest scores $(M=17.36$, 
$S D=4.08)$ and the mothers $(\mathrm{SG})$ with the highest scores $(M=22.38, S D=5.87)$. The Bonferroni KSP T-scale shows a significant effect on the scale of somatic anxiety (KSPSAT) between the mothers in the DG and the SG at the level $p<0.05$. Data are displayed in Figure 2 .

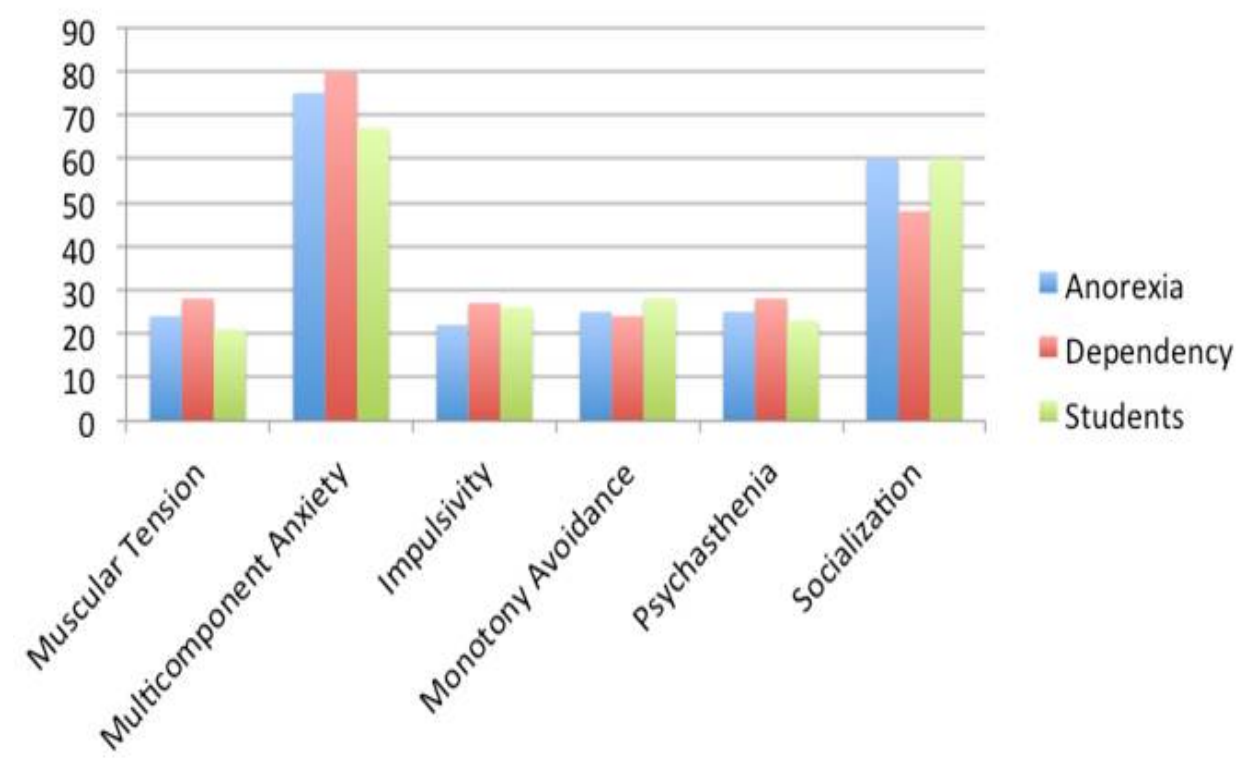

Figure 1. Comparisons Between the Daughters-KSP ANOVA (only significant differences displayed).

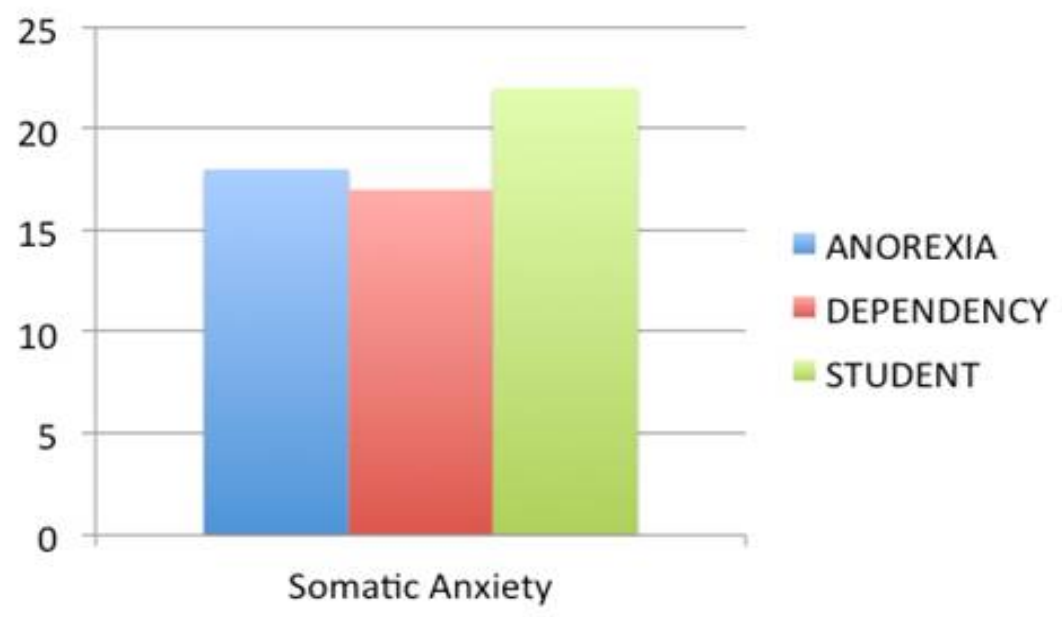

Figure 2. Comparisons between the Mothers-KSP ANOVA (only significant differences displayed).

\section{Comparison Within the Family}

ANOVAs were also calculated for differences between family members in the three groups. Data are not displayed.

\section{The Anorectic Group}

For the anorectic women there were significant effects on the scales of somatic anxiety (KSPSA), psychic anxiety (KSPPA), muscular tension (KSPMT), multicomponent anxiety (KSPMCA), psychastenia (KSPPS) at the level of $p<0.001$, irritability (KSPIRR) at the level of $p<0.01$, suspicion (KSPS) and hostility (KSPHOST) at the level of $p<0.05$. 
Bonferroni post hoc tests showed significant differences between the daughter and the father on the scales of somatic anxiety (KSPSA), psychic anxiety (KSPPA), muscular tension (KSPMT), multicomponent anxiety (KSPMCA), and psychastenia (KSPPS) at the level of $p<0$. 001, irritability at the level of $p<0.01$, suspicion (KSPS) hostility (KSPHOST) at the level of $p<0.05$. All differences were in the direction of more problems for the women.

Significant differences were also found between the daughter and the mother on the scales of somatic anxiety (KSPSA), psychic anxiety (KSPPA) and multicomponent anxiety (KSPMCA) at the level of $p<0.01$, muscular tension (KSPMT) and irritability (KSPIRR) at the level $p<0.05$.

A significant difference between the father and the mother on the scale of multicomponent anxiety (KSPMCA) at the level $p<0.05$ was also found with more anxiety reported by the mothers.

Bonferroni post hoc tests T-scores showed significant differences between daughter and the father on the scale of impulsivity (KSPIT) at the level of $p<0.05$, but nothing was found on the raw scores. For data see Figure 3.

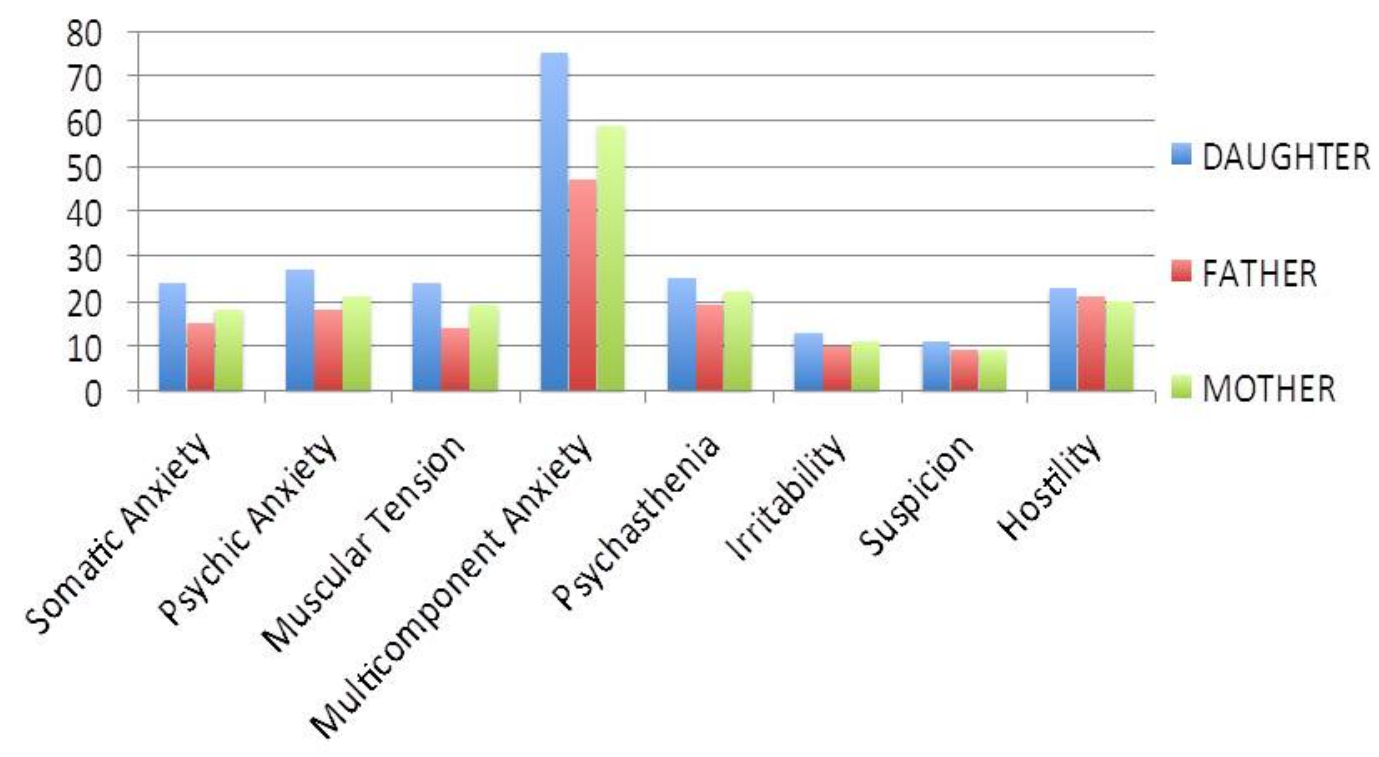

Figure 3. Comparison Within the Anorexia Family_KSP ANOVA (only significant differences displayed).

\section{The Drug-Dependency Group}

For the women with drug-dependency problems, their fathers and their mothers, there were significant effects for the scales of somatic anxiety (KSPSA), psychic anxiety (KSPPA), muscular tension (KSPMT), multicomponent anxiety (KSPMCA), psychastenia (KSPPS), socialization (KSPSO), and aggression (KSPAGG), indirect aggression (KSPIA), verbal aggression (KSPVA), irritability (KSPIRR), guilt (KSPG) and hostility (KSPHOST).

Post hoc tests showed differences for the scales of somatic anxiety (KSPSA), muscular tension (KSPMT), multicomponent anxiety (KSPMCA), psychastenia (KSPPS) between daughter and father and daughter and mother. All these differences were in the direction of more problems among the women.

Women reported higher scores than their mothers on the scales of socialization (KSPSO), guilt (KSPG) and hostility (KSPHOST) (all $p<0.05$ or less). Women reported higher scores than their fathers on the scales 
of verbal aggression (KSPVA) and irritability (KSPIRR), and higher scores than their fathers and mothers on the scales of indirect aggression (KSPIA) and aggression (KSPAGG) (all $p<0.05$ or less). Data are displayed in Figure 4.

\section{The Student Group}

Significant effects were found in the scales of somatic anxiety (KSPSA), muscular tension (KSPMT) and multicomponent anxiety (KSPMCA) and psychic anxiety (KSPPA) (all $p<0.05$ or less). Post hocs showed that the women differed from the mothers on the scales of somatic anxiety (KSPSA), muscular tension (KSPMT) and multicomponent anxiety (KSPMCA) (all $p<0.05$ or less). Moreover, a difference was found between the fathers and the mothers on the scale of psychic anxiety (KSPPA) at the level $p<0.05$, with the mothers reporting more anxiety. For data see Figure 5.

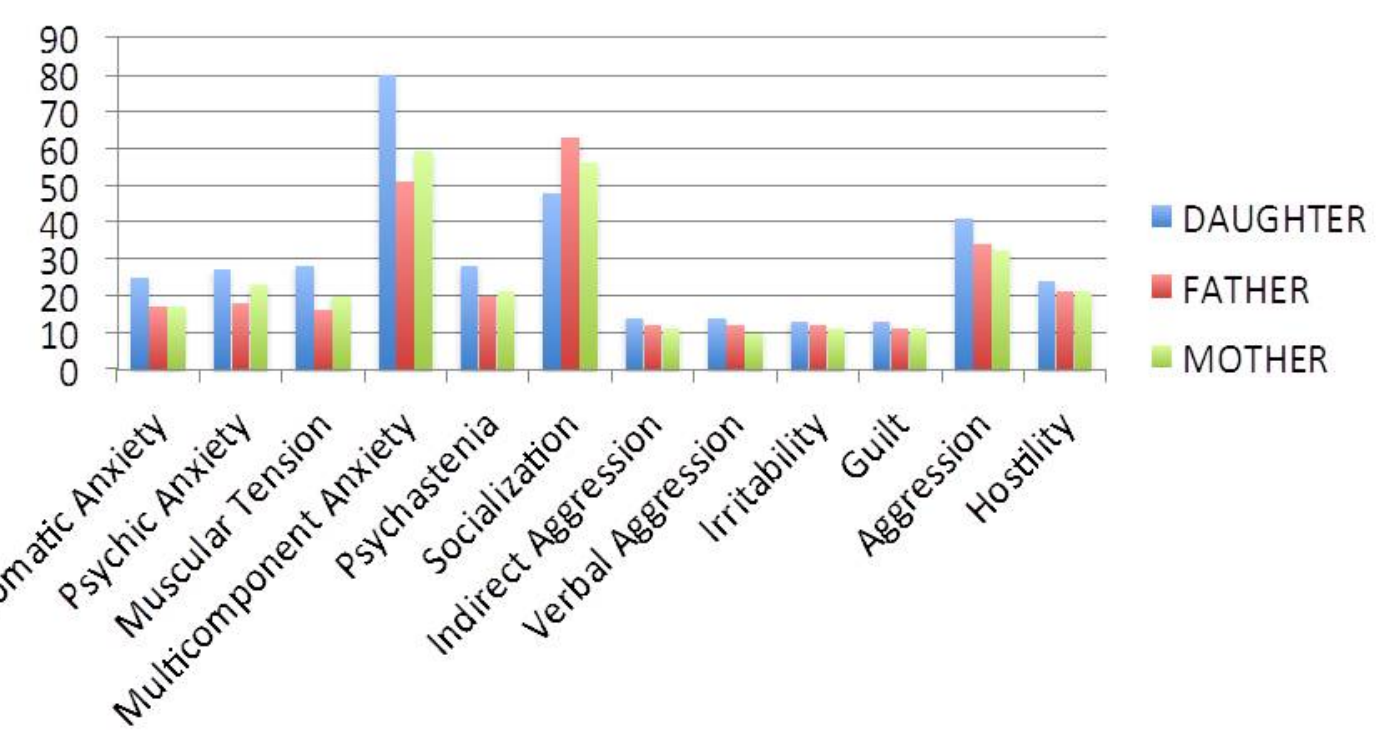

Figure 4. Comparison Within the Drug-Dependency Family—KSP ANOVA (only significant differences displayed).

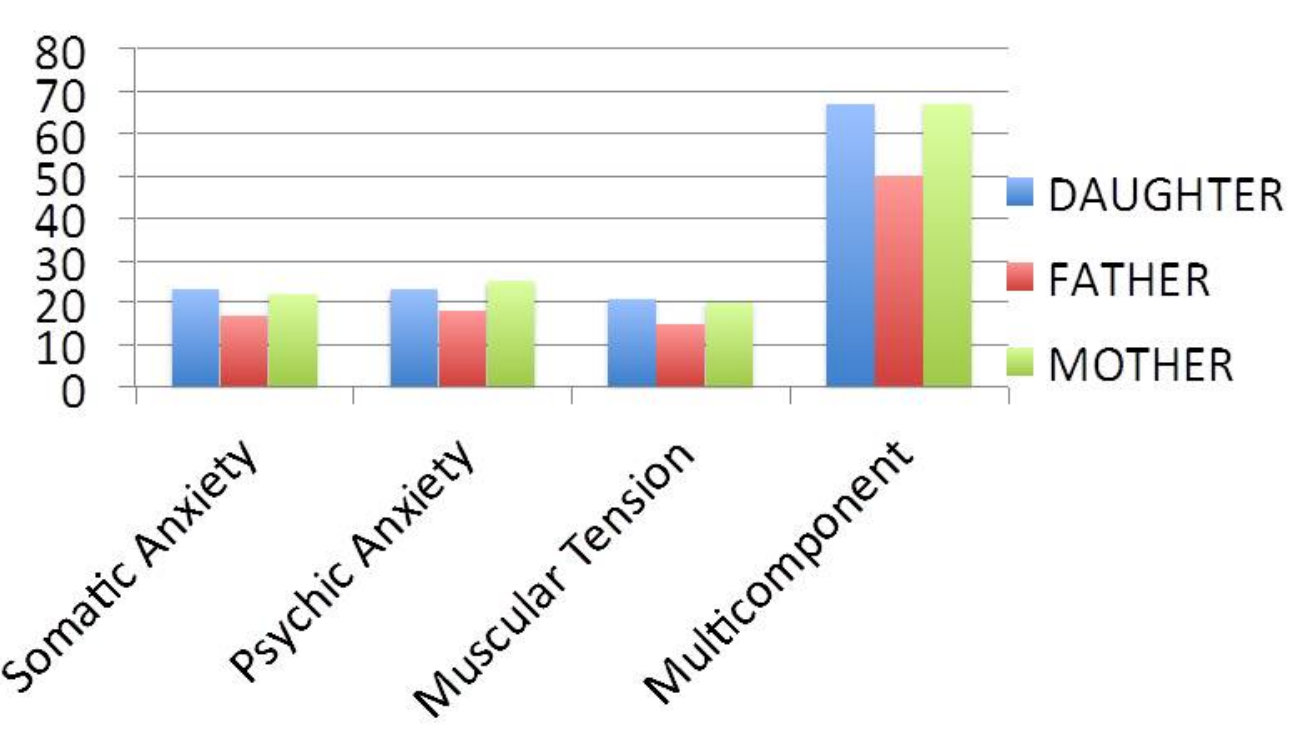

Figure 5. Comparison Within the Student Family—KSP ANOVA (only significant differences displayed). 


\section{Discussion}

The aim of this study was to investigate self-reported psychological distress in anorectic women, their fathers and mothers. Two additional groups of young women (drug-dependence respectively student group) and their parents were also included. The largest differences of the psychological distress were found in the three groups of young women. The study shows that anorectic women reported higher level of psychological distress compared to the student group, but lower level compared to the drug-dependence group.

No differences in psychological distress were found among the three groups of fathers, but minor differences were found among the three groups of mothers. The mothers of the anorectic women reported higher degree of somatic anxiety compared to the mothers of the drug-dependency women but lower than the mothers of the students.

Differences in psychological distress within families were also tested. The anorectic women were more distressed, in comparison to their mothers and fathers. The mothers in all three groups showed more anxiety than the fathers.

\section{Interpretation}

Several studies confirm that anorectic women have higher level of psychological distress. The biological aspects of KSP in the study of Ahrén-Moonga et al. (2011) showed that the biological responses to stress, anxiety states and starvation include, for example, elevations of interleukins as an immunological response. Ahrén-Moonga et al. (2011) showed that the anorectic women had significantly higher scores than the controls on scales measuring Somatic Anxiety, Muscular Tension and Psychic Anxiety. Also the women with eating disorders scored higher in the study by Ravi, Forsberg, Fitzpatrick, and Lock (2009), than women without eating disorders on the scales of anxiety. Augestad, Saether, and Götestam (1999), showed in her study that high school students with AN and BN scored higher on anxiety than those without eating disorder.

Compared with the AG and the SG with no significant effects on the aggression scales, the DG had elevated scores on them. Östlund, Spak, and Sundh (2004) found in her study comparing women with alcohol dependence, that they reported higher irritability and impulsiveness with more extreme scores than the general population.

An interesting fact was that no differences were found among all the variables of the fathers in all three groups. This result could indicate that the anorectic women do not have fathers with elevated psychological distress, but it could also be due to a small sample size and only self-report measures and a selected sample. Two studies in China showed that the fathers, being more rational in their coping style, were less disturbed and distressed than the mothers (Ma, 2015).

The mothers' in all the groups had similar scores on the somatic anxiety scale. The finding in this study of comparison within the group was that the mothers in all three groups had more anxiety than the fathers. According to a private communication with family therapists, they found that mothers with non-problematic children had more anxiety and the problems with the other mothers were that they showed a lack of anxiety for their children

When comparing within the families we found hostility and irritability between the anorectic women and their fathers. Horesh, Sommerfeld, Wolf, Zubery, and Zalsman (2015) found that "fathers' negative attributes were significantly associated with ED and depressive symptom". Nielsen (2015) pointed in her research that the 
quality of the father-daughter relationship was associated with young women's rates of clinical depression and eating disorders - the highest rates seen in the daughter's early adult years. In opposition to the above, Fäldt Ciccolo (2008) when looking at the varieties of qualities within family functioning found the patient group ( $\mathrm{AN}$ and $\mathrm{BN}$ ) did not significantly express more hostility and criticism than the control group. Demidenko et al. (2014) found that there were more negative feelings in the description of the father by the depressed than by the non-depressed woman in their relation to their fathers when comparing adolescent girls 13-19 and their fathers.

The consequences of starvation with the obsessive thoughts are well known as the Minnesota Starvation Experiment showed (Kalm \& Semba, 2005). The question of what is predisposing and what is actually a consequence of the eating disorder, is brought up by several authors (Ahrén-Moonga et al., 2008; Strober \& Johnson, 2012). Augusted et al. (1999) found that the length of time of the anorectic state was closely related to the hostility scores in fathers. Increasing rates of hostility scores in parents with increased duration of AN, this could be viewed as a response to the presence of the disorder or as maintaining factor. The research by Ravi et al. (2009) found that the parents with a child with AN would have higher levels of psychopathology but significantly lower than outpatient psychiatric norms. She also brings up the question whether a family psychopathology is playing a role in the development or if it may represent familial response to AN. Mental illness over an extended period of time introduces numerous stressors into parents' lives.

The ability to be conscious about both own and others affects is a state or trait in subgroups of patients diagnosed with eating disorders (AN, BN). The findings of Lech, Holmqvist, and Andersson (2012) showed that the levels of observer-rated affect consciousness were not correlated with self-reported eating pathology or psychopathology. The quality study by Sibeoni et al. (2014) of the process of differentiation among families with anorectic daughters in comparison with families with normal daughters found that in the anorectic group concentrated only on the relation among the family member and did not address the question of the peer group.

\section{Limitations}

The study has several limitations. First, the sample size was small rendering limited statistical power to detect differences. Second, we had a selected sample and only self-report measures. Third, we only studied the women and their fathers and mothers. It would have been interesting to have data on siblings, friends and grandparents who also may be important for women with AN. Fourth the response options are fixed and therefore has to fit into the response alternatives.

\section{Conclusions}

In spite of these limitations the study has its importance as its results gives some directions of the experiences of individuals in close relation and touches the role of the father, a less researched subject. It can then be used for further studies on the father and daughter relation.

This study may contribute to help clarifying the awareness of psychological distress as experienced by each participant and also in relation to the others in the same family as well as to the same gender group. The results could also help to distinguish the similarity and the differences between the three groups and within each group. In conclusion, the study illustrates the importance of studying the mothers and fathers of women with anorexia. Larger studies are needed to further investigate the role of the family relations in AN. 


\section{References}

af Klinteberg, B., Schalling, D., \& Magnusson, D. (1986). Self-report assessment of personality traits. Data from the KSP inventory on a representative sample of normal male and female subjects within a development project. Reports from the Project Individual Development and adjustment (No. 64), Department of Psychology. Stockholm University, Sweden.

Ahrén-Monga, J., Lekander, M., von Blixen, N., Rönnelid, J., Holmgren, S., \& af Klinteberg, B. (2011). Levels of tumour necrosis factor-alpha and interleukin-6 in severely ill patients with eating disorders. Neuropsychobiology, 63(1), 8-14.

Ahrén-Monga, J., Holmgren, S., Knorring, L., \& Klinteberg, B. (2008). Personality traits and self-injurious behaviour in patients with eating disorders. European Eating disorders Review, 16, 268-275.

American Psychiatric Association. (2000). Diagnostic and statistical manual-IV-TR. Arlington, V.A.: APA.

Augestad, L. B., Saether, B., \& Götestam, K. G. (1999). The relationship between eating disorders and personality in physically active women. Scand J. Med. Sci. Sports, 9(5), 304-312.

Bornstein, R. (1993). Parental representations and psychopathology: A critical review of the empirical literature. In J. M. Masling, \& R. F. Bornstein (Eds.), Psychoanalytic perspectives on psychopathology. Washington D. C.: American Psychological Association.

Botta, R. A., \& Dumlao, R. (2002). How do conflict and communication patterns between fathers and daughter contribute to or offset eating disorder? Health Communication, 14, 199-219.

Dåderman, A. M., Hellström, A., Wennberg, P., \& Törestad, B. (2005). Using the Karolinska Scales of Personality on male juvenile delinquents: Relationship between scales and factor structure. Nord J. Psychiatry; 59, 448-456.

Demidenko, N., et al. (2014). Father-Daughter attachment and communication in depressed and nondepressed adolescent girls. $J$. Child Fam Stud, 24, 1727-1734.

Eme, F. R., \& Danielak, M. H. (1995). Comparison of fathers and daughters with and without maladaptive eating attitudes. Journal of Emotional and behavioral Disorders, 3(1), 40-45.

Engel, K., \& Stienen, M. (1988). Father types of anorexia nervosa patients: The "bonding", the "brutal", the "weak" and the "absent" father. An empirical study based on a comparison with fathers of a representative normal group. Psychotherapy Psychosomatics, 49, 145-152.

Fäldt Ciccolo, E. B. (2008). Exploring experience of family relations by patients with anorexia nervosa and bulimia nervosa using a projective family test. Psychological Reports, 103, 231-242.

Gale, C. J., Cluett, E. R., \& Laver-Bradbury, C. (2013). A review of the father-child relationship in the development and maintenance of adolescent anorexia and bulimia nervosa. Issues Compr Pediatr Nurs., 1-2, 48-69.

Gustavsson, J. P. (1997). Stability and validity of self-reported personality traits: Contributions to the evaluation of the Karolinska scales of personality (KSP). Department of Clinical Neuroscience, Psychiatry Section and the Institute for Environmental Medicine, Karolinska Institute, Stockholm, Sweden.

Horesh, N., Sommerfeld, E., Wolf, M., Zubery, E., \& Zalsman, G. (2015). Father-daughter relationship and the severity of eating disorders. European Psychiatry, 30, 114-120.

Jeammet, P., Gorge, A., Zweifel, R., \& Flavigny, H. (1973). Le milieu familial des anorexiques mentaux: Incidences sur le traitement. Annales Médicales interne, 124(3), 247-252.

Kalm, L. M., \& Semba, R. D. (2005). They starved so that others be better fed: Remembering ancel keys and the minnesota experiment. J. Nutr., 135(6), 1347-1352.

Lech, B., Holmqvist, R., \& Andersson, G. (2012). Affect consciousness and eating disorders: Short term stability and subgroup characteristics. Eur. Eat. Disorder Rev., 20, e50-e55.

Ma, J. L. C. (2015). The father's roles in the recovery of young Chinese suffering from anorexia nervosa in two Chinese cities, Hong Kong and Shenzhen. Journal of Family Therapy, 37, 61-78. doi: 10.1111/1467-6427.12037

Nielsen, L. (2015). Young adult daughters' relationships with their fathers: Review of recent research. Marriage \& Family Review, 50(4), 360-372.

Östlund, A., Spak, F., \& Sundh, V. (2004). Personality traits in relation to alcohol dependence and abuse and psychiatric comorbidity among women: A population-based study. Substance Use \& Misuse, 39(9), 1301-1318.

Phares, V. (1992). Where is Poppa? The relative lack of attention to the role of fathers in child and adolescent psychopathology. American Psychologist, 47(5), 656-664.

Phares, V. (2005). Still looking for Poppa. American Psychologist, 735-736. 
Ravi, S., Forsberg, S., \& Fitzpatrick, L. J. (2009). Is there a relationship between parental self-reported psychopathology and symptom severity in adolescents with anorexia nervosa? Eating Disorders, 17, 63-71.

Schalling, D., Åsberg, G., Edman, G., \& Oreland, L. (1987). Markers for vulnerability to psychopathology: Temperament traits associated with platelet MAO activity. Acta Psychiatrica Scandinavica, 76, 172-182.

Schalling, D., \& Edman, G. (1987). Personality and vulnerability to psychopathology: The development of the Karolinska Scales of Personality (KSP). Manual in preparation.

Sibeoni, J., et al. (2014). Nourriture et relations familiales chez des adolescents avec et sans anorexie mentale: une étude qualitative par Photo-élicitation (Food and family relationships among adolescents with and without Anorexia Nervosa: A qualitative study using Photo-elicitation). Annales Médico-Psychologiques, 172, 708-713.

Strober, M., \& Johnson, C. (2012). The need for complex ideas in Anorexia Nervosa: Why biology, environment, and psyche all matter, why therapists make mistakes, and why clinical benchmarks are needed for managing weight correction. Int. J. Eat Disord, 45, 155-178.

World Health Organization. (2007). ICD-10 Classification of mental and behavioural disorders (2007 edition). London: Churchill Livingstone. 